Florida State University College of Law

Scholarship Repository

Scholarly Publications

$12-2011$

\title{
Welfare Enhancing Regulation Exemptions
}

Murat C. Mungan

Florida State University College of Law

Follow this and additional works at: https://ir.law.fsu.edu/articles

Part of the Law and Economics Commons

\section{Recommended Citation}

Murat C. Mungan, Welfare Enhancing Regulation Exemptions, 31 INT'L REV. L. \& ECON. 249 (2011), Available at: https://ir.law.fsu.edu/articles/118

This Article is brought to you for free and open access by Scholarship Repository. It has been accepted for inclusion in Scholarly Publications by an authorized administrator of Scholarship Repository. For more information, please contact efarrell@law.fsu.edu. 


\title{
Welfare Enhancing Regulation Exemptions*
}

\author{
Murat C. Mungan ${ }^{\dagger}$ \\ Boston College, Department of Economics \\ and \\ George Mason University School of Law
}

November 7, 2010

\begin{abstract}
Sanctions for regulation violations are used to deter conduct which could potentially result in great social harms. This practice over-deters talented entities and under-deters untalented entities, which leads to social losses. This paper analyzes whether and how such social losses can be mitigated. I show that this can be achieved by allowing regulatees to purchase passes exempting them from regulations at appropriate prices.
\end{abstract}

Keywords: Regulations, optimal deterrence, exemptions.

\section{Introduction}

Regulations are often used to overcome the judgment proof offender problem by deterring conduct which could potentially result in great social harms. ${ }^{1}$ Common examples include safety and corporate regulations. The objective of most regulations in these fields is to prevent or decrease the probability of harm by illegalizing certain conduct which are deemed to be dangerous.

${ }^{*}$ I would like to thank an anonymous referee, and the participants of the 2010 EALE conference for useful comments and suggestions. The usual disclaimer applies.

${ }^{\dagger}$ George Mason University School of Law, 3301 Farifax Dr, Arlington, VA, USA. E-mail: mmungan@gmu.edu.

${ }^{1}$ See Shavell (1993 p. 279) observing the same fact. See also, Shavell (1986 p. 45), where the author describes the judgment proof problem: "Parties who cause harm to others may sometimes turn out to be 'judgment proof,' that is, unable to pay fully the amount for which they have been found legally liable." 
The dangerousness of conduct, however, may depend on the party committing it. A skilled worker is less likely to fall from a ladder which does not satisfy safety standards, than a new worker. Moral hazard may pose less of a threat to family companies than to professionally managed companies. A building located on top of a hill may be more or less threatened by potential earthquakes. Hence, expected harms caused by non-compliance with standards regulating dangerous conduct may depend on the characteristics of the non-complying party. Furthermore, the cost of complying with regulations may vary across parties. Providing records and detailed accounting reports of company activities may be more expensive for an investor than for an exporter, or vice versa. Therefore, the expected social benefit of having a regulatee comply with a particular regulation depends on that particular regulatee's characteristics. ${ }^{2}$

It would be ideal if entities were to comply with regulations if and only if the expected social benefit from their compliance were positive. But, since uniform sanctions apply to all entities violating regulations, it is impossible to provide incentives to regulatees which produce this ideal result. $^{3}$ Uniform sanctions under-deter regulatees, who create non-trivial risks of social harm by violating regulations, but for whom compliance is very costly. Similarly, uniform sanctions over-deter regulatees, for whom compliance is not very costly, but who generate quite low risks by violating regulations.

Over-deterrence, as well as under-deterrence, is socially undesirable. Social costs arising from these problems can be mitigated by allowing entities to opt-out of regulations at an appropriate price. Purchasers of such 'passes' would be shielded from sanctions for violating regulations, but not from sanctions for causing harm. As such, only those entities who have a small chance of causing harm by violating regulations would purchase passes. Therefore, some regulatees who would otherwise be over-deterred can be incentivized to purchase passes and engage in the regulated conduct.

This last point can be demonstrated by a simple example. Consider a regulation which requires

\footnotetext{
${ }^{2}$ See Shavell (1984 pp. 365-366) making a similar observation.

${ }^{3}$ See Shavell (1990) for a statement and proof of this impossibility in the context of punishment of attempts. The author's analysis is equally applicable for analyzing regulations, and is re-produced in section 2.A.
} 
firms to comply with certain accounting regulations to eliminate potential fraud. The sanction is $\$ 200 K$ for regulation violations, and $\$ 1 M$ for fraud. If a firm violates the regulation, it is detected with a probability of 0.5 . If an employee commits fraud, such fraud is also detected and penalized with a probability of 0.5. Assume for simplicity that compliance with regulations guarantees that employees will not commit fraud. Now consider two firms, $A$ and $B$. If firm $A[B]$ violates the regulation, its employees may commit fraud with a probability of 0.3 [0.1]. In this example, if exemption passes were sold at $\$ 80 K$, only firm $B$, the high talent firm, would potentially buy it. This simple example demonstrates how passes can be appropriately priced to mitigate over-deterrence by shielding high-talented firms from sanctions for harmless regulation violations.

Absent exemption passes, it would be undesirable to set sanctions for regulations as high as possible, because such sanctions would lead to high costs associated with over-deterrence. In other words, absent passes, sanctions for regulation violations would be chosen to balance costs of overdeterrence and under-deterrence on the margin. But when exemptions are possible, as argued, costs of over-deterrence are mitigated. As such, sanctions for regulation violations can be increased to eliminate some level of under-deterrence. Hence, exemption passes can be used to reduce underdeterrence as well as over-deterrence.

Administering a regulatory system which allows for such exemptions may, however, be more costly than one which does not. Accordingly, welfare gains from eliminating over-deterrence and under-deterrence must be high enough for the administration of purchasable regulation exemptions to be socially desirable. Such welfare gains are likely to be high in cases where the regulation seeks to prevent extreme social harms, and therefore requires very costly compliance measures. Corporate regulations, such as those implemented pursuant to the Sarbanes-Oxley Act, are likely to fall under this category.

It should also be noted that harms resulting from regulation violations must be detectable for exemption passes to be operationalized. This requirement is unlikely to be met in the context of many environmental regulations. Consider, for example, waste disposal. Law enforcers may be 
able to observe whether an entity has violated regulations. It is, however, difficult or too costly to ascertain whether such violations were harmful. Therefore, it is not possible to differentiate between sanctions for harmful and harmless regulation violations. As such, it becomes impossible to shield high talent regulatees only from harmless regulation violations, making it impossible to operationalize exemption passes.

In sum, shielding high-talent regulatees from harmless regulation violations by allowing them to purchase exemption passes can mitigate problems of over and under-deterrence. Accordingly, when it is possible to differentiate between harmful and harmless regulation violations, such passes are welfare enhancing if their administration costs do not off-set gains from reducing over and underdeterrence.

In the next section, I formalize these intuitive ideas by using a deterrence model, and identify the optimal price for exemption passes. ${ }^{4}$ Section 3 discusses the scope of the analysis and concludes. An Appendix at the end contains mathematical proofs of propositions in section 2.

\section{Model and Analysis}

An individual has the option of engaging in regulated conduct which may cause harm $(h)$. If the individual complies with regulations by incurring compliance costs of $c$, then his conduct will surely be harmless. ${ }^{5} c$ varies among individuals and is distributed over $[0, \infty)$. If an individual violates the regulation, the likelihood of his conduct being harmful is $q \in[0,1]$, which represents his talent.

An individual who violates the regulation can be caught and sanctioned. The probability of detection may depend on whether or not the regulation violation results in harm. $p_{1}$ and $p_{2}$ respectively denote the probability with which non-harm and harm will be sanctioned. ${ }^{6}$ I am assuming

\footnotetext{
${ }^{4}$ For a review of deterrence models in the context of law enforcement, see Polinsky and Shavell (2000) and Garoupa (1997).

${ }^{5}$ This is a harmless and simplifying assumption. In reality, compliance with regulations may only decrease the probability of harm, and not eliminate it entirely. To incorporate this observation, it is sufficient to interpret $h$ as the maximum reduction in expected harm through compliance with regulations.

${ }^{6} \mathrm{I}$ am assuming that $p_{1}$ and $p_{2}$ are determined exogenously. This assumption can be justified due to the use of general as opposed to specific law enforcement as defined in Shavell (1991). See also footnote 12 in Mungan (2010)
} 
that $p_{2} \geq p_{1}$, which reflects the fact that observation of harm increases the likelihood of detection.

How offenders are punished depends on whether or not individuals may purchase passes which exempt them from regulations. Sub-sections A and B, respectively, describe sanction schemes when regulation exemptions cannot be purchased, and when they can. It is assumed in both cases that sanctions may not exceed a maximum fine of $w<h$, reflecting the fact that there are judgment proof offenders.

\section{A. Law Enforcement without Passes}

When exemption passes are not available, an offender is punished with a sanction of $s_{1}$ for regulation violations which do not result in harm. On the other hand, if the conduct results in harm, the offender can be punished more severely at $s_{2} \geq s_{1}$. This case is referred to as the NoExemption Regime. In this regime, and individual has a simple choice between complying with and violating the regulation. An individual with talent $q$ faces expected sanctions of $S_{n}(q)$ by violating the regulation:

$$
S_{n}(q)=(1-q) p_{1} s_{1}+q p_{2} s_{2}
$$

where $(1-q) p_{1}$ reflects the probability that he will not cause harm, be caught and sanctioned for a harmless regulation violation. Similarly $q p_{2}$ reflects the probability that he will cause harm and be subject to sanctions for causing harm.

On the other hand, an individual has to incur costs of $c$ to comply with regulations. Hence, an individual with talent $q$ and compliance $\operatorname{costs} c$ violates the regulation if:

$$
c>S_{n}(q)=(1-q) p_{1} s_{1}+q p_{2} s_{2}
$$

Furthermore, an individual with $q$ generates an expected social harm of $q h$ when he violates the regulation. Hence, the first best solution would require that individuals violate regulations iff ${ }^{7}$ :

$$
c>q h
$$

for a brief list of other articles employing similar assumptions.

${ }^{7} \mathrm{I}$ am ignoring indifferent individuals with $c=q h$, since their behaviour does not effect welfare. 
An initial an immediate observation is that the first best solution cannot be attained. Even if sanctions were chosen as high as possible deterrence would be inadequate for some individuals due to problems of judgment proofness. To see this, note that the first best solution requires that individuals with $q=1$ comply with regulations if $c<h$. However, an individual with $q=1$, even when fines are maximal, will violate regulations if $c>S_{n}(1)=p_{2} w$. Hence, individuals with $q=1$ and $c$ such that $h>c>p_{2} w$ will violate regulations, although it is socially desirable that they comply. This observation illustrates the fact that a degree of under-deterrence is inevitable for untalented individuals (i.e. $q$ close to 1 ).

Moreover, when regulation violations are not sanctioned (i.e. $s_{1}=0$ ), there is no over-deterrence. This can be observed by noting that

$$
S_{n}(q)=q p_{2} s_{2}<q h, \text { for all } q
$$

An implication of this observation is that if $s_{1}$ is held constant at 0 , increasing $s_{2}$ to the maximal fine would be desirable, because this would minimize under-deterrence and would not cause overdeterrence. Finally, given that $s_{2}=w, s_{1}$ should be chosen to balance costs of under and overdeterrence on the margin, which would occur at a positive value of $s_{1}$.

These observations allow the characterization of the Best No-Exemption Solution by the following proposition.

Proposition 1: When there are no exemption passes, (i) the best punishment scheme punishes harmful conduct with the maximal sanction (i.e. $s_{2}^{*}=w$ ), (ii) there are social costs associated with under-deterrence as well as over-deterrence, and (iii) sanctions for harmless regulation violations (i.e. $\left.s_{1}^{*}\right)$ optimally trade-off over-deterrence for under-deterrence.

Proof: See Shavell (1990 p. 464) proof of proposition 2. The analysis of the No-Exemption Regime is identical to the analysis of optimal punishments for attempts in Shavell (1990).

The most important result summarized by proposition 1 is that the Best No-Exemption Solution produces social costs associated with over-deterrence and under-deterrence. The next sub-sections 
describe exemption passes and how they can be priced to mitigate such social costs.

\section{B. Welfare Enhancing Purchasable Exemptions}

A potential way to mitigate problems of over and under-deterrence is to allow individuals to purchase exemption passes at appropriate prices. Formally, when an individual purchases a pass, he makes an up-front payment of $y_{e}$ and is not sanctioned for harmless regulation violations but is subject to a sanction of $y_{2}$ for harm. Hence, when he causes harm and is caught, he loses a total of $y_{h} \equiv y_{e}+y_{2}$. An individual, who does not purchase a pass, faces punishments of the type described in the No-Exemption Regime. However, to distinguish (optimal) sanctions imposed under the No-Exemption and Purchasable Exemptions regimes, sanctions for individuals who do not purchase passes under the Purchasable Exemptions Regime will be denoted as $z_{1}$ and $z_{2}$.

Using this notation, expected costs attached to an individual's three options under the Purchasable Exemptions Regime are given by:

$$
\begin{gathered}
S_{e}(q)=y_{e}+q p_{2} y_{2} \\
S_{v}(q)=(1-q) p_{1} z_{1}+q p_{2} z_{2} ; \text { and } \\
S_{c}(c)=c
\end{gathered}
$$

where $S_{e}, S_{v}$ and $S_{c}$, respectively, represent expected costs associated with purchasing an exemption pass, violating regulations without purchasing an exemption pass, and complying with regulations. ${ }^{8}$

By comparing $S_{e}$ and $S_{v}$, one thing that is immediately observed is that $S_{v}$ is likely to be greater for talented individuals. This is because, when an individual does not purchase an exemption pass, the probability of being sanctioned for harmless regulation violations (i.e. $\left.(1-q) p_{1}\right)$ are increasing in talent. Moreover, the values of $S_{e}$ and $S_{v}$ are relevant only for high $c$ individuals, because only they will violate regulations. Therefore, one can choose sanctions and the price of exemption passes

\footnotetext{
${ }^{8} \mathrm{I}$ am ignoring the possibility of purchasing an exemption pass and complying with regulations, since if one is to comply there is no benefit to purchasing an exemption pass.
} 
such that only individuals above a certain talent threshold $q_{o} \in(0,1)$ purchase them. Furthermore, by choosing $z_{i \in\{1,2\}}=s_{i \in\{1,2\}}^{*}$, one can guarantee that low talent individuals (i.e. $q>q_{o}$ ) have the same incentives as they do under the Best No-Exemption Solution.

Given these observations, it follows that by appropriately choosing the price of exemption passes, and therefore $q_{o}$, one can mitigate over-deterrence, without affecting under-deterrence. ${ }^{9}$ This naturally leads to an increase in welfare. Proposition 2 summarizes these results.

Proposition 2: The Best No-Exemption Solution can be improved upon by allowing individuals to purchase exemption passes at an appropriate price.

Proof: See Appendix.

Proposition 2 verifies the claim that exemption passes can be used to increase welfare. It relies on the fact that one can mitigate over-deterrence without affecting under-deterrence. It does not, however, identify the characteristics of an optimal Purchasable Exemptions Regime. The next subsection is devoted to this purpose.

\section{Optimal Schemes with Purchasable Exemptions}

When exemption passes are not available, it is (generally) undesirable to set sanctions for regulations as high as possible, because such sanctions would lead to high costs associated with overdeterrence. ${ }^{10}$ Stated differently, under the Best No-Exemption Solution, sanctions for regulations (i.e. $\left.s_{1}^{*}\right)$ would be chosen to balance costs of over-deterrence and under-deterrence on the margin. When exemptions are possible, however, as demonstrated in the previous sub-section, costs of over-deterrence can be mitigated through exemption passes. Therefore, sanctions for regulation violations can be increased to eliminate some level of under-deterrence, and the amount of overdeterrence caused by such increases can be off-set by decreasing the price of exemption passes.

\footnotetext{
${ }^{9}$ See the appendix showing that sanctions and the price of passes can be chosen such that $q_{o}=\frac{p_{1} s_{1}^{*}}{h+p_{1} s_{1}^{*}-p_{2} w}$, which is the described threshold talent level.

${ }^{10}$ Theoretically, in cases where the maximum punishment for harmful conduct results in extreme inadequate deterrence, maximum sanctions for regulations can be desirable. In reality, however, the punishment for regulation violations are not as high as the punishment for harmful conduct.
} 
Hence, under a Purchasable Exemptions Regime, it is optimal to increase the punishment for regulation violations as much as possible. In other words, the optimal sanction for harmless as well as harmful regulation violations committed by individuals without exemption passes is maximal.

Proposition 3 summarizes this observation, and characterizes the optimal punishment scheme under the Purchasable Exemptions Regime.

Proposition 3: Under the optimal Purchasable Exemptions Regime:

(i) there is a cut-off talent level $q_{C}$ such that only (talented) individuals with $q<q_{C}$ purchase passes,

(ii) individuals with $q=q_{C}$ are under-deterred,

(iii) those who do not purchase exemption passes are punished with the maximal fine for harmful as well as harmless regulation violations, i.e. $z_{1}^{*}=z_{2}^{*}=w$,

(iv) those who purchase exemption passes are punished with the maximal fine for harmful regulation violations, i.e. $y_{h}=w$,

(v) the price of exemption passes is positive but less than the maximal fine $0<y_{e}<w$,

(vi) $y_{e}$ is that price which optimally trades-off under-deterrence with over-deterrence.

There is an interesting implication of Proposition 3. Although one would suspect that allowing individuals to purchase exemption passes would increase regulation violations by providing a discount for harmless regulation violations, this need not be the case. It is true that under the optimal solution, talented individuals are provided with greater incentives to violate regulations. But it is also true that untalented individuals are deterred more through the use of maximal fines for harmless regulation violations. Hence, the overall effect on the number of regulation violations depends on the talent distribution.

\section{Discussion and Conclusion}

In the previous section, I showed that exemption passes can be used to mitigate over and underdeterrence. In doing so, I made the implicit assumption that harms resulting from regulation violations are detectable. Furthermore, I ignored administrative costs. In this section, I discuss the 
implications of unobservable harms and administrative costs, and how these considerations affect the scope of the model previously presented.

\section{A. Level of Generality: Attempts and Bounded Compliance Costs}

Harmless regulation violations and attempts share a lot in common. In both cases, the actor has engaged in conduct which could have, but has not, resulted in harm. Nevertheless, I have intentionally excluded criminal attempts from the scope of this paper. This is mainly because I believe that criminal attempts are distinguishable from regulations violations in a very important manner. In order to analyze ordinary attempts, one should focus on offenders whose benefits are conditional on inflicting harm. That is to say, it should be assumed that a person ordinarily shoots at her victim hoping that the bullet hits him, and not hoping that she misses her target. On the other

hand, a person not complying with accounting regulations ordinarily does so to avoid compliance costs.

This distinction is crucial in determining optimal-deterrence policies. If potential offenders are assumed to derive benefits that are smaller than the harm they will cause by hurting their victims, then there will be no such thing as over-deterrence in the context of criminal attempts. To formalize this idea and show the validity of this claim, consider the following simple notation:

$b^{-}$is the benefit of that individual who derives the most benefit from crime.

$h$ is the harm associated with the completed crime, with $h>b^{-}$

$q$ is the likelihood that an offender will succeed in completing his crime.

In this framework, an individual with benefit $b$ from crime is over-deterred if the following simple inequality holds:

$$
\text { Individual's Expected Benefit }=q b>q h=\text { Expected Social Cost }
$$

However, as noted $h>b^{-}$and by definition $b^{-} \geq b$. Accordingly, in this framework, overdeterrence is not possible.

It could be argued that the same result is likely to hold for regulation violations if one is to 
assume $c^{-}<h$. This argument is flawed. As pointed out, when analyzing regulation violations it should be assumed that individuals care about cost avoidance and not about inflicting social harm. Accordingly, in the context of regulation violations, an individual who complies with regulations is over-deterred if:

$$
c>q h=\text { Expected Social Cost }
$$

which holds if $q<\frac{c}{h}$.

Therefore, individuals who are highly talented will be over-deterred under a regime that sanctions regulation violations. This should demonstrate that the main rationale provided in the previous section extends to cases where the benefit derivable from the regulation violation is bounded from above.

\section{B. Level of Generality: Environmental Regulations}

In the previous section, I have implicitly assumed that harms inflicted through regulation violations are perfectly observable. In the context of many environmental regulations this assumption is unlikely to hold. Consider, for instance, waste disposal. One may be able to observe whether regulation violations have taken place. It is, however, difficult or too costly to observe whether such violations have caused substantial harm. When harm is not easily observable, it is no longer possible to differentiate between sanctions for harmful and harmless regulation violations. As such, even if entities were to possess different talents in disposing of waste, the model presented in the previous section becomes inapplicable.

\section{Administrative Costs}

Administering a Purchasable Exemptions Regime can be expensive. Accordingly, the desirability of such a regime depends on whether the benefits it offers (from the mitigation of over and underdeterrence) off sets its administrative costs. The variable costs of administering such a regime seem to be relatively small. It only requires simple purchases of passes, and keeping records of entities which have purchased such passes. The determination of appropriate prices for passes may require 
substantial and fixed research costs. On the other hand, benefits from mitigating over and underdeterrence increase in the size of expected social harms and costs of complying with regulations. As such, in cases where the regulation seeks to prevent extreme social harms, and therefore requires very costly compliance measures, a Purchasable Exemptions Regime would be socially desirable.

Other sources of cost savings associated with exemption passes have been formalized in the context of self-reporting. ${ }^{11}$ In particular, regulatory agencies would not have to devote resources to detect harmless regulation violations by entities which have purchased exemption passes. This would result in substantial savings from enforcement costs. These savings make exemption passes more desirable.

\section{Conclusion}

In a very simple framework, I have shown that allowing individuals to purchase passes exempting them from sanctions for harmless regulation violations can mitigate problems of under and overdeterrence.

For such passes to be operational, however, it is required that harms caused by regulation violations be easily observable. Therefore, it is unlikely that exemption passes could be used to eliminate over and under-deterrence in the context of many environmental regulations, where harm is difficult to observe.

Moreover, administering a Purchasable Exemptions Regime may be expensive. These costs can be off-set by reductions in enforcement costs resulting from the lack of need to detect exempted parties for harmless regulation violations, and by benefits associated with mitigating under and over-deterrence.

Due to these reasons, whether it is desirable to allow entities to purchase exemption passes for

\footnotetext{
${ }^{11}$ See Kaplow and Shavell (1994) for a general analysis of self-reporting in law enforcement, where the authors show that self-reporting "offers two advantages over schemes without self-reporting: enforcement resources are saved because individuals who report their harmful acts need not be detected, and risk is reduced because individuals who report their behavior bear certain rather than uncertain sanctions." Kaplow and Shavell (1994, p. 583).
} 
a particular regulation is an empirical question. However, in the context of corporate accounting and record keeping regulations, where the costs of under and over-deterrence are relatively large, exemption passes are likely to increase welfare. Whether such passes would be desirable in other fields, such as safety regulations, is a question which can only be answered after a careful comparison of the administrative costs and functional benefits of such passes.

\section{Appendix}

\section{Notation:}

$s_{1}, s_{2} \geq 0$ : Sanction, under the No-Exemption Regime, for harmless and harmful regulation violations respectively.

$z_{1}, z_{2} \geq 0$ : Sanction, under the Purchasable Exemptions Regime, for non-exempted harmless and harmful regulation violations respectively.

$y_{e} \geq 0$ : Price for purchasing an exemption pass.

$y_{2} \geq 0$ : Additional sanction, under the Purchasable Exemptions Regime, for non-exempted and harmful regulation violations.

$y_{h} \equiv y_{e}+y_{2}$.

(.; .): List describing a No-Exemption Regime, where the components of the list describe values of $s_{1}$ and $s_{2}$, and in that order.

(.;.;.;.) List describing a Purchasable Exemptions Regime, where the components of the list describe values of $z_{1}, z_{2}, y_{e}$, and $y_{2}$, and in that order.

$p_{1}$ : Probability of detection of a harmless regulation violation.

$p_{2}$ : Probability of detection of a harmful regulation violation.

$h$ : Harm associated with harmful regulation violation.

$q$ : An individual's likelihood of causing harm upon violating regulations.

$H(q) \equiv q h$

$c$ : Cost of complying with regulations.

$w<h$ : Maximal fine. 
Proposition 2: The Best No-Exemption Solution can be improved upon by allowing individuals to purchase exemption passes at an appropriate price.

Proof: $\left(s_{1}^{*} ; w\right)$ describes the Best No-Exemption Solution, where $s_{1}^{*} \leq w$. This solution is derived in Shavell (1990), and individuals' incentives under this solution is represented in Figure 1a. Next, define regime $O$, the Over-Deterrence Mitigating Regime:

$$
O \equiv\left(s_{1}^{*} ; w ; y_{e}^{O} ; y_{2}^{O}\right)
$$

where

$$
y_{e}^{O}=\frac{p_{1} s_{1}^{*}\left[h-p_{2} w\right]}{\left[1-p_{2}\right] p_{1} s_{1}^{*}+\left[h-p_{2} w\right]}
$$

and

$$
y_{2}^{O}=\left[w-y_{e}^{O}\right]
$$

In $O$, sanctions for non-exempted regulation violations are identical to those in the Best No-Exemption Solution. Accordingly, the expected cost of not purchasing an exemption and violating the regulation (i.e. $S_{v}(q)$ as defined in (6)) equals the expected cost of engaging in the illegalized act under the Best No-Exemption Solution (i.e. $S_{n}(q)$ as defined in (1)):

$$
S_{v}(q)=S_{n}(q)=(1-q) p_{1} s_{1}^{*}+q p_{2} w
$$

On the other hand, the expected cost of purchasing an exemption pass and violating the regulation is given by:

$$
S_{e}(q)=q p_{2}\left[w-y_{e}^{O}\right]+y_{e}^{O}
$$

The cost of compliance is c.

Figures 1b-d represent expected social harm $(H(q)), S_{v}(q)$ and $S_{e}(q)$ as a function of $q$, and the talent level $q_{O}$ at which these functions intersect. Through simple algebra one can verify that the figures accurately represent the intersection point of all three curves and their slopes. More precisely, one can verify that

$$
\text { (i) } q_{O}=\frac{p_{1} s_{1}^{*}}{h+p_{1} s_{1}^{*}-p_{2} w} \text {, }
$$


(ii) $S_{v}\left(q_{O}\right)=S_{e}\left(q_{O}\right)=H\left(q_{O}\right)$,

and (iii) $S_{e}\left(q_{O}\right)$ has a greater slope than $S_{v}\left(q_{O}\right)$. These claims can be verified by following the steps below:

$$
S_{v}\left(q_{O}\right)=\left(1-q_{O}\right) p_{1} s_{1}^{*}+q_{O} p_{2} w=\frac{h}{h+p_{1} s_{1}^{*}-p_{2} w}=q_{O} p_{2}\left(w-y_{e}^{O}\right)+y_{e}^{O}=S_{e}\left(q_{O}\right)
$$

which can be verified by plugging in the expressions for $q_{O}$ in (A.6.) and the expression for $y_{e}^{O}$ in (A.2.) into the expressions for $S_{v}(q)$ and $S_{e}(q)$.

(ii) (A.8.) reveals that $S_{v}\left(q_{O}\right)=S_{e}\left(q_{O}\right)$, hence showing that $S_{v}\left(q_{O}\right)=q_{O} h$, should suffice to verify the claim in (A.7.). Using (A.4), we have that

$$
S_{v}\left(q_{O}\right)=\left(1-q_{O}\right) p_{1} s_{1}^{*}+q_{O} p_{2} w=q_{O} h \text { iff } p_{1} s_{1}^{*}=q_{O}\left(h+p_{1} s_{1}^{*}-p_{2} w\right)
$$

Plugging in the value for $q_{O}$ as provided in (A.6.) reveals that (A.9.) holds.

(iii) (A.4) and (A.5) imply that the slopes of $S_{v}\left(q_{O}\right)$ and $S_{e}\left(q_{O}\right)$ are respectively given by $\left(p_{2} w-\right.$ $\left.p_{1} s_{1}^{*}\right)$ and $p_{2}\left(w-y_{e}^{O}\right)$. Hence, the claim holds iff $p_{1} s_{1}^{*}>p_{2} y_{e}^{O}$. But the expression for $y_{e}^{O}$ as provided in (A.2) reveals that $p_{1} s_{1}^{*}>y_{e}^{O}$. Hence, $S_{e}\left(q_{O}\right)$ has a greater slope than $S_{v}\left(q_{O}\right)$.

Hence, the cost curves in Figures 1b-d are accurate representations. Therefore, they can be used to determine the behavior of individuals with various talent levels and benefits. This is achieved through the next three observations.

Observation 1: Individuals for which $\min \left\{S_{e}(q), S_{v}(q)\right\} \geq c$ find it in their best interest to comply with regulations, since this is the least costly option. These individuals are represented by the white area in Figure $1 \mathrm{c}$.

Observation 2: For individuals with $q<q_{O}$, it follows that $S_{e}(q)<S_{v}(q)$, hence they will either choose to purchase exemptions or comply with regulations. For individuals with $c>S_{e}(q)$ the former option is more profitable, hence these individuals choose to purchase exemptions. These individuals are represented by the shaded area in Figure $1 b$. 
Observation 3: $S_{e}(q)>S_{v}(q)$ for individuals with $q>q_{O}$, hence these individuals do not purchase exemption passes, and those with $c>S_{v}(q)$ violate regulations.

These three observations are incorporated in Figures 1a-d. It follows from these figures that incentives provided in the Best No-Exemption Solution and regime $O$ differ from each other only for individuals in the triangular region $A B C$. These individuals incur compliance costs in the Best No-Exemption Solution but they do not in regime O. Since, $c>$ qh for these individuals, O improves upon the Best No-Reporting Solution by decreasing over-deterrence. Q.E.D.

The following Lemmas are useful in proving Proposition 3.

Lemma 1: A Purchasable Exemptions Regime $\left(z_{1}^{\prime} ; z_{2}^{\prime} ; y_{e}^{\prime} ; y_{2}^{\prime}\right)$ such that $p_{1} z_{1}^{\prime} \leq y_{e}^{\prime}$ and $p_{2} z_{2}^{\prime} \leq$ $p_{2} y_{2}^{\prime}+y_{e}^{\prime}$ is sub-optimal.

Proof: In this case, $S_{e}(q) \geq S_{v}(q)$ for all $q$, hence nobody purchases an exemption pass. Therefore, the No-Exemption Regime $\left(z_{1}^{\prime} ; z_{2}^{\prime}\right)$ achieves the same social welfare as $\left(z_{1}^{\prime} ; z_{2}^{\prime} ; y_{e}^{\prime} ; y_{2}^{\prime}\right)$. By definition the Best No-Exemption Solution produces at least as much social welfare as $\left(z_{1}^{\prime} ; z_{2}^{\prime}\right)$. But regime O, as defined in Proposition 2, dominates the Best No-Exemption Solution, and is not a regime that satisfies the condition of Lemma 1. Accordingly, $\left(z_{1}^{\prime} ; z_{2}^{\prime} ; y_{e}^{\prime} ; y_{2}^{\prime}\right)$ is sub-optimal. Q.E.D.

Lemma 2: A Purchasable Exemptions Regime $\left(z_{1}^{\prime} ; z_{2}^{\prime} ; y_{e}^{\prime} ; y_{2}^{\prime}\right)$ such that $p_{1} z_{1}^{\prime} \geq y_{e}^{\prime}$ and $p_{2} z_{2}^{\prime} \geq$ $p_{2} y_{2}^{\prime}+y_{e}^{\prime}$ is sub-optimal.

Proof: In case both constraints hold with equality Lemma 1 implies that $\left(z_{1}^{\prime} ; z_{2}^{\prime} ; y_{e}^{\prime} ; y_{2}^{\prime}\right)$ is suboptimal. When at least one constraint holds with inequality, it must be the case that $S_{v}(q)>S_{e}(q)$ for almost all $q$, hence almost every individual with $c>S_{e}(q)$ purchases an exemption pass. Denote by I the point where $S_{e}(q)$ intersects $H(q)$. Next, observe that $y_{h}^{\prime}=y_{e}^{\prime}+y_{2}^{\prime}<w$ must hold. Otherwise, $p_{2} y_{2}^{\prime}+y_{e}^{\prime}>p_{2} w \geq p_{2} z_{2}^{\prime}$, which is a violation of the condition stated in Lemma 2. But when $y_{h}^{\prime}<w$ one can rotate $S_{e}(q)$ counter-clockwise around point $I$, by appropriately decreasing $y_{e}^{\prime}$ to some $y_{e}^{\prime \prime}$ and increasing $y_{2}^{\prime}$ to $y_{2}^{\prime \prime}=w-y_{e}^{\prime \prime}$. The new expected cost curve obtained by this rotation is denoted as $S_{e}^{n}(q)$ in Figure 2. 
[Insert Figure 2]

As reflected in Figure $2,\left(z_{1}^{\prime} ; z_{2}^{\prime} ; y_{e}^{\prime \prime} ; y_{2}^{\prime \prime}\right)$ results in lower under and over-deterrence than $\left(z_{1}^{\prime} ; z_{2}^{\prime} ; y_{e}^{\prime} ; y_{2}^{\prime}\right)$, and $p_{2} z_{2}^{\prime}<p_{2} y_{2}^{\prime \prime}+y_{e}^{\prime \prime} \cdot{ }^{12}$ Hence, $\left(z_{1}^{\prime} ; z_{2}^{\prime} ; y_{e}^{\prime} ; y_{2}^{\prime}\right)$ is sub-optimal. Q.E.D.

Lemma 3: An optimal Purchasable Exemptions Regime $\left(z_{1}^{*} ; z_{2}^{*} ; y_{e}^{*} ; y_{2}^{*}\right)$ must be such that $p_{1} z_{1}^{*}>$ $y_{e}^{*}$ and $p_{2} z_{2}^{*}<p_{2} y_{e}^{*}+y_{2}^{*}$.

Proof: Lemma's 1 and 2 together imply that any optimal Purchasable Exemptions Regime must satisfy either

$$
p_{1} z_{1}^{*}<y_{e}^{*} \text { and } p_{2} z_{2}^{*}>p_{2} y_{2}^{*}+y_{e}^{*}
$$

or

$$
p_{1} z_{1}^{*}>y_{e}^{*} \text { and } p_{2} z_{2}^{*}<p_{2} y_{2}^{*}+y_{e}^{*}
$$

Assume $\left(z_{1}^{\prime} ; z_{2}^{\prime} ; y_{e}^{\prime} ; y_{2}^{\prime}\right)$ satisfies (A.10). In this case there are two possibilities. Either (i) $S_{e}(q)$ and $S_{v}(q)$ intersect at some point below (or at) the curve $H(q)$ or (ii) they intersect above it.

(i) If $S_{e}(q)$ and $S_{v}(q)$ intersect below (or at) $H(q)$, another Purchasable Exemptions Regime described as $\left(z_{1}^{\prime} ; z_{2}^{\prime} ; w ; 0\right)$ dominates $\left(z_{1}^{\prime} ; z_{2}^{\prime} ; y_{e}^{\prime} ; y_{2}^{\prime}\right)$, since it results in less under-deterrence but the same level of over-deterrence. Hence, $\left(z_{1}^{\prime} ; z_{2}^{\prime} ; y_{e}^{\prime} ; y_{2}^{\prime}\right)$ cannot be optimal if it satisfies (A.10) and the intersection of $S_{e}(q)$ and $S_{v}(q)$ occurs below (or at) $H(q)$. These results are reflected in Figure 3, where $S_{e}^{n}(q)$ denotes the the cost of purchasing exemptions under $\left(z_{1}^{\prime} ; z_{2}^{\prime} ; w ; 0\right)$.

\section{[Insert Figure 3]}

(ii) If $S_{e}(q)$ and $S_{v}(q)$ intersect above $H(q)$, then one can design a new Purchasable Exemptions Regime, by keeping $z_{2}^{\prime}, y_{e}^{\prime}$, and $y_{2}^{\prime}$ constant, but decreasing $z_{1}^{\prime}$ to $z_{1}^{\prime \prime}$, such that the new expected cost curve (denoted in Figure 4 as $S_{v}^{n}(q)$ ) intersects $S_{e}(q)$ at $H(q)$. In this case $\left(z_{1}^{\prime \prime} ; z_{2}^{\prime} ; y_{e}^{\prime} ; y_{2}^{\prime}\right)$ dominates $\left(z_{1}^{\prime} ; z_{2}^{\prime} ; y_{e}^{\prime} ; y_{2}^{\prime}\right)$, since it results in less over-deterrence but the same level of under-deterrence. Hence,

\footnotetext{
${ }^{12}$ Figure 2 illustrates a case where both conditions in Lemma 2 hold strictly. It is easy to verify that the analysis is not affected when either condition holds with equality.
} 
$\left(z_{1}^{\prime} ; z_{2}^{\prime} ; y_{e}^{\prime} ; y_{2}^{\prime}\right)$ cannot be optimal if it satisfies $(A .10)$ and the intersection of $S_{e}(q)$ and $S_{v}(q)$ occurs above $H(q)$. These results are reflected in Figure 4.

\section{[Insert Figure 4]}

These two observations reveal the fact that a Purchasable Exemptions Regime satisfying (A.10) cannot be optimal. Therefore, the optimal Purchasable Exemptions Regime must satisfy (A.11). Q.E.D.

Proposition 3: Under the optimal Purchasable Exemptions Regime:

(i) there is a cut-off talent level $q_{C}$ such that only (talented) individuals with $q<q_{C}$ purchase passes,

(ii) individuals with $q=q_{C}$ are under-deterred,

(iii) those who do not purchase exemption passes are punished with the maximal fine for harmful as well as harmless regulation violations, i.e. $z_{1}^{*}=z_{2}^{*}=w$,

(iv) those who purchase exemption passes are punished with the maximal fine for harmful regulation violations, i.e. $y_{h}=w$,

(v) the price of exemption passes is positive but less than the maximal fine $0<y_{e}<w$,

(vi) $y_{e}$ is that price which optimally trades-off under-deterrence with over-deterrence.

\section{Proof:}

(i) An individual purchases an exemption pass only if $S_{e}(q)<\min \left\{S_{v}(q), c\right\}$. Lemma 3 implies that the optimal Purchasable Exemptions Regime satisfies (A.11). In this case, $S_{e}(q)$ and $S_{v}(q)$ intersect at some talent level $q_{C}$, and $S_{v}(q)>S_{e}(q)$ for all individuals with $q<q_{C}$. Hence, only individuals with $q<q_{C}$ and $S_{e}(q)<c$ purchase exemption passes.

(ii) Lemma 3 implies that the optimal Purchasable Exemptions Regime satisfies (A.11). In this case, $S_{v}(q)$ and $S_{e}(q)$ can intersect below (or at) the curve $H(q)$ or above it.

Consider a regime $\left(z_{1}^{\prime} ; z_{2}^{\prime} ; y_{e}^{\prime} ; y_{2}^{\prime}\right)$, where $S_{v}(q)$ and $S_{e}(q)$ intersect above $H(q)$. A new Purchasable Exemptions Regime can be designed by decreasing $y_{e}^{\prime}$ to $y_{e}^{\prime \prime}$ such that the new expected cost 
curve, denoted as $S_{e}^{n}(q)$ in Figure 5 , intersects $S_{v}(q)$ at $H(q)$. In this case $\left(z_{1}^{\prime} ; z_{2}^{\prime} ; y_{e}^{\prime \prime} ; y_{2}^{\prime}\right)$ dominates $\left(z_{1}^{\prime} ; z_{2}^{\prime} ; y_{e}^{\prime} ; y_{2}^{\prime}\right)$, because it results in less over-deterrence. Hence, the optimal Purchasable Exemptions Regime must be such that $S_{v}(q)$ and $S_{e}(q)$ intersect below (or at) $H(q)$. Furthermore, as the proof of part (v) and (vi) will reveal, a Purchasable Exemptions Regime where $S_{v}(q)$ and $S_{e}(q)$ intersect at $H(q)$ is sub-optimal. Therefore, under the optimal Purchasable Exemptions Regime individuals with $q=q^{C}$ are under-deterred.

\section{[Insert Figure 5]}

(iii) Part (ii) establishes the fact that $S_{v}(q)$ and $S_{e}(q)$ intersect below (or at) $H(q)$. Any such Purchasable Exemptions Regime $\left(z_{1}^{\prime} ; z_{2}^{\prime} ; y_{e}^{\prime} ; y_{2}^{\prime}\right)$, where $z_{1}^{\prime}<w$ or $z_{2}^{\prime}<w$, is sub-optimal. To see this, note that increasing $z_{1}$ and $z_{2}$ leads to less under-deterrence at no additional cost (i.e. additional over-deterrence). This can be verified by Figure 6, which shows that an increase in $z_{1}^{\prime}$ or $z_{2}^{\prime}$ leads to a reduction in under-deterrence.

\section{[Insert Figure 6]}

(iv) Denote by I the point at which $S_{v}(q)$ and $H(q)$ intersect. Next, note that whenever $y_{2}+y_{e}<$ $w$, the expected cost curve $S_{e}(q)$ can be rotated counter-clockwise around point I by increasing $y_{2}$ and decreasing $y_{e}$. Furthermore, it is easy to note the increase in $y_{2}$ must be more than the decrease in $y_{e}$ to achieve such rotation. Otherwise, $S_{e}(1)=y_{e}+p_{2} y_{2}$ would be decreased, which would be a contradiction with the fact that the rotation is counter-clockwise. Hence, such rotation requires an increase in $y_{h}$. Next, note that such rotation is socially desirable, since it leads to less underdeterrence and over-deterrence. This is illustrated via Figure 7 Therefore, such rotation should be continued until $y_{h}$ achieves its maximum level, namely $w$.

\section{[Insert Figure 7]}

(v) and (vi) Given properties (i)-(iv), all that remains to be determined is $y_{e}^{*}$, since the optimal Purchasable Exemptions Regime is of the form $\left(w ; w ; y_{e}^{*} ; w-y_{e}^{*}\right)$. Moreover, properties (i)-(iv) imply 
the following condition: Curves $S_{v}(q)$ and $S_{e}(q)$ must intersect at some point below (or at) $H(q)$. This condition places an upper bound on the choice of $y_{e}^{*}$. To see this note that $q_{C}$, the talent level at which the intersection of $S_{v}(q)$ and $S_{e}(q)$ occur, is a function of $y_{e}$. In particular, in the following way:

$$
q_{C}\left(y_{e}\right)=\frac{\left[w p_{1}-y_{e}\right]}{\left[w p_{1}-p_{2} y_{e}\right]}
$$

(A.12) implies that $\frac{d q_{C}}{d y_{e}}<0, q_{C}\left(p_{1} w\right)=0$, and $q_{C}(0)=1$. Next, denote by $q_{D}$, the talent level at which curves $H(q)$ and $S_{v}(q)=(1-q) p_{1} w+q p_{2} w$ intersect. It is clear that $q_{D} \in(0,1)$. Now, the intermediate value theorem can be invoked to state that there exists some $y_{e}^{C} \in\left(0, p_{1} w\right)$ such that $q_{C}\left(y_{e}^{C}\right)=q_{D}$. Since $\frac{d q_{C}}{d y_{e}}<0$, it must be the case that $y_{e}^{*} \leq y_{e}^{C}$, otherwise curves $S_{v}(q)$ and $S_{e}(q)$ will intersect above the curve $H(q)$, which is a contradiction with the optimality requirement identified in part (ii). Therefore, the welfare maximization problem can be expressed as ${ }^{13}$ :

$$
\begin{gathered}
\max _{y_{e} \in\left(0, y_{e}^{C}\right]} W\left(y_{e}\right)= \\
\max _{y_{e} \in\left(0, y_{e}^{C}\right]}\left[\int_{0}^{q_{C}\left(y_{e}\right)} \int_{S_{e}\left(q, y_{e}\right)}^{\infty}(c-q h) f(b) d b g(q) d q+\int_{q_{C}\left(y_{e}\right)}^{1} \int_{S_{v}(q)}^{\infty}(b-q h) f(b) d b g(q) d q\right]
\end{gathered}
$$

where

$$
\begin{gathered}
S_{e}\left(q, y_{e}\right)=q p_{2} w+\left[1-q p_{2}\right] y_{e}, \text { and } \\
S_{v}(q)=w\left[(1-q) p_{1}+q p_{2}\right]
\end{gathered}
$$

$f$ and $g$ respectively denote the density functions associated with compliance costs and talent levels, and $S_{e}=S_{e}\left(q, y_{e}\right)$ reflects the dependency of $S_{e}$ on the choice of $y_{e}$.

Differentiating $W$ with respect to $y_{e}$, yields:

$$
W_{y_{e}}=-\int_{0}^{q_{C}\left(y_{e}\right)}\left(1-q p_{2}\right)\left(S_{e}\left(q, y_{e}\right)-q h\right) f\left(S_{e}\left(q, y_{e}\right)\right) g(q) d q
$$

Next, note that

$$
W_{y_{e}}\left(y_{e}^{C}\right)<0
$$

\footnotetext{
${ }^{13} W$ is maximized over $\left(0, y_{e}^{C}\right]$, because $y_{e}=0$ would be a violation of the requirement identified by Lemma 3 .
} 
since the integrand is positive for all $q<q_{C}\left(y_{e}^{C}\right)$. And similarly,

$$
W_{y_{e}}(0)>0
$$

since the integrand is negative for all $q<q_{C}(0)$.

Hence, $y_{e}^{*}$, must satisfy:

$$
w>y_{e}^{*}>0
$$

and

$$
W_{y_{e}}\left(y_{e}^{*}\right)=0
$$

which implies that the optimal price for exemption passes is positive, smaller than the optimal fine, and optimally trades-off under-deterrence with over-deterrence. Q.E.D.

\section{References}

[1] Garoupa, N. 1997, The Theory of Optimal Law Enforcement, Journal of Economic Surveys, 11, $267-95$.

[2] Kaplow, L. and Steven S. 1994, Optimal Law Enforcement with Self-Reporting of Behavior, Journal of Political Economy, 102, 583-606.

[3] Mungan, M. C. 2010, Repeat Offenders: If They Learn, We Punish Them More Severely, International Review of Law and Economics, 30, 173-177.

[4] Polinsky, A. M. and S. Shavell. 2000, The Economic Theory of Public Enforcement of Law. Journal of Economic Literature, 38, 45-76.

[5] Shavell, S. 1984, Liability for Harm versus Regulation of Safety, The Journal of Legal Studies, $13,357-374$.

[6] Shavell, S. 1986, The Judgment Proof Problem, International Review of Law and Economics, 6, 45-58. 
[7] Shavell, S. 1990, Deterrence and the Punishment of Attempts, The Journal of Legal Studies, 19, 435-466.

[8] Shavell, S. 1991, Specific versus General Enforcement of Law, Journal of Political Economy, 99, 1088-1108.

[9] Shavell, S. 1993, The Optimal Structure of Law Enforcement, Journal of Law and Economics, $36,255-287$. 


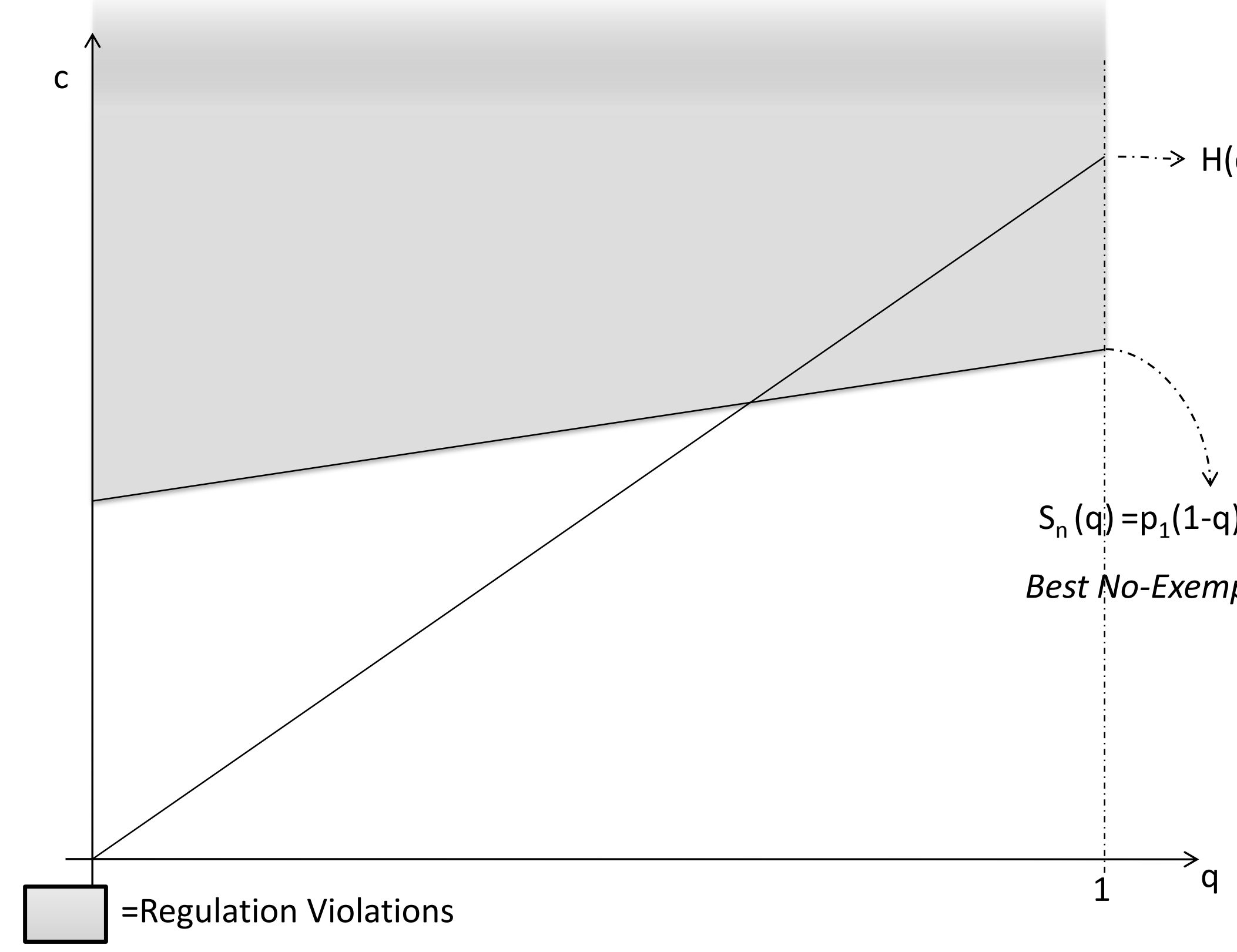

Figure 1c: Purchasable Exemption Regime 'O' (Over-Deterrence Mitigating) Regulation Violations

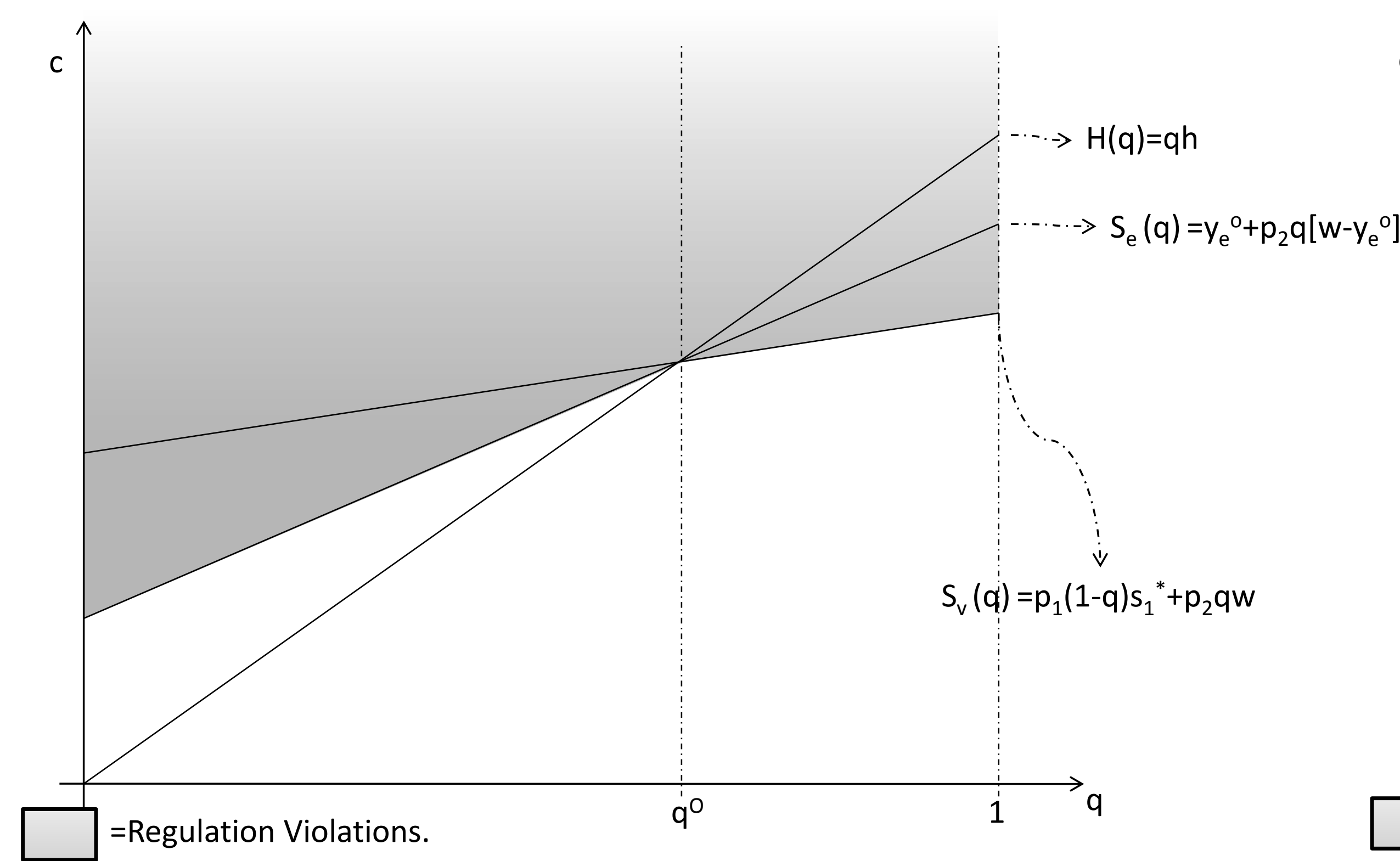

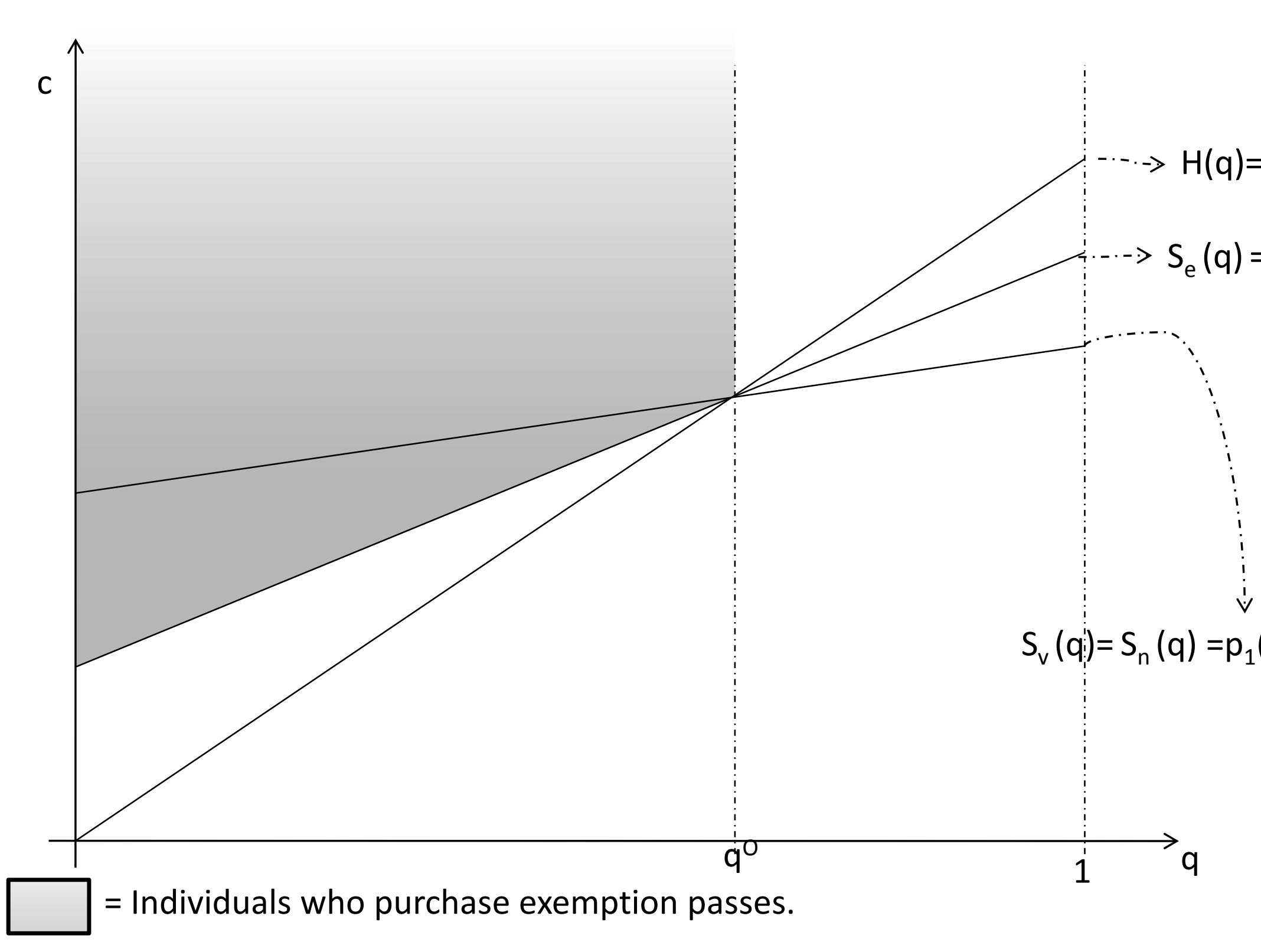

Figure 1d: Purchasable Exemption Regime ' $O$ ' (Over-Deterrence Mitigating) Reduction in Over-Deterrence

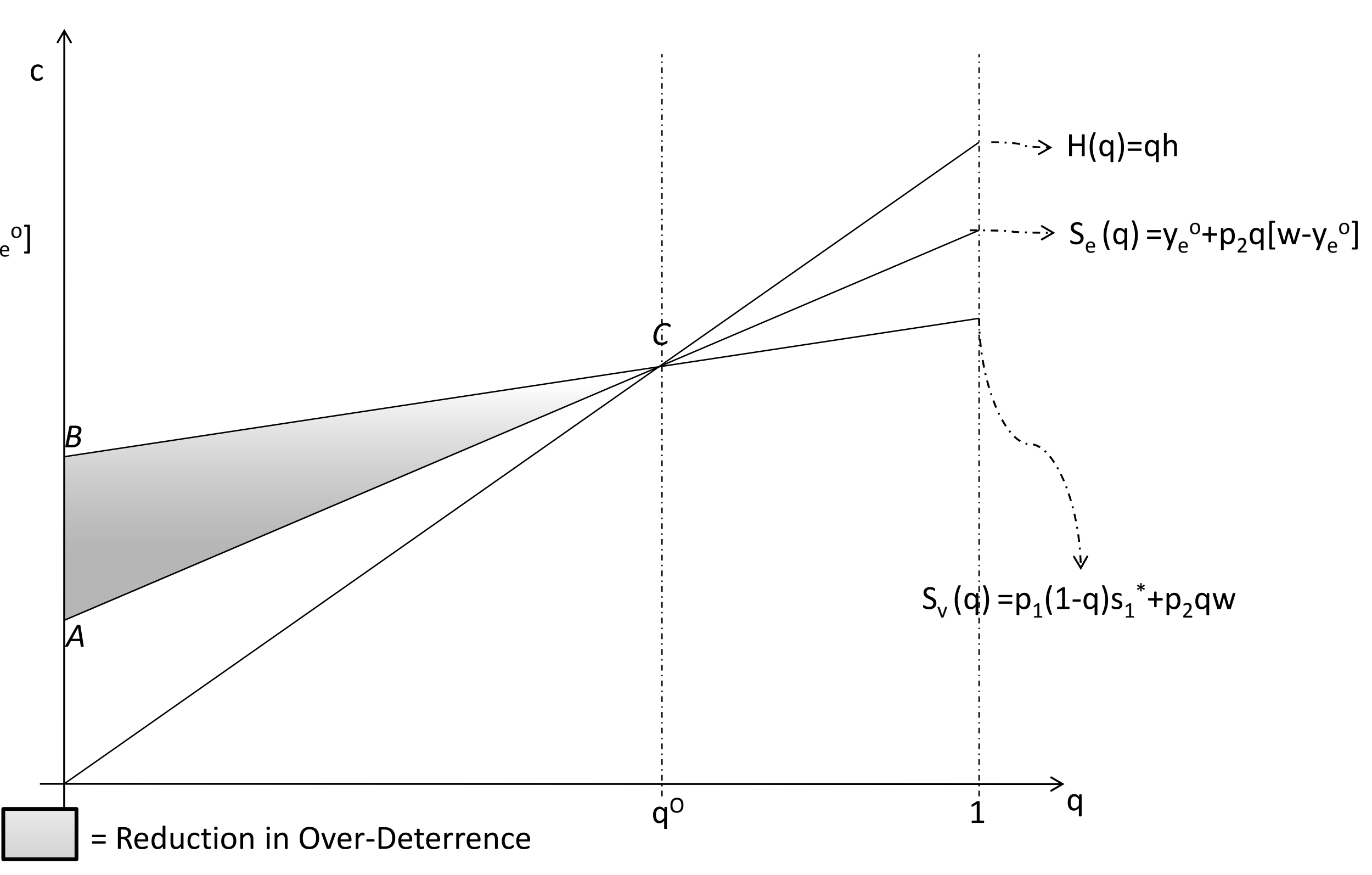




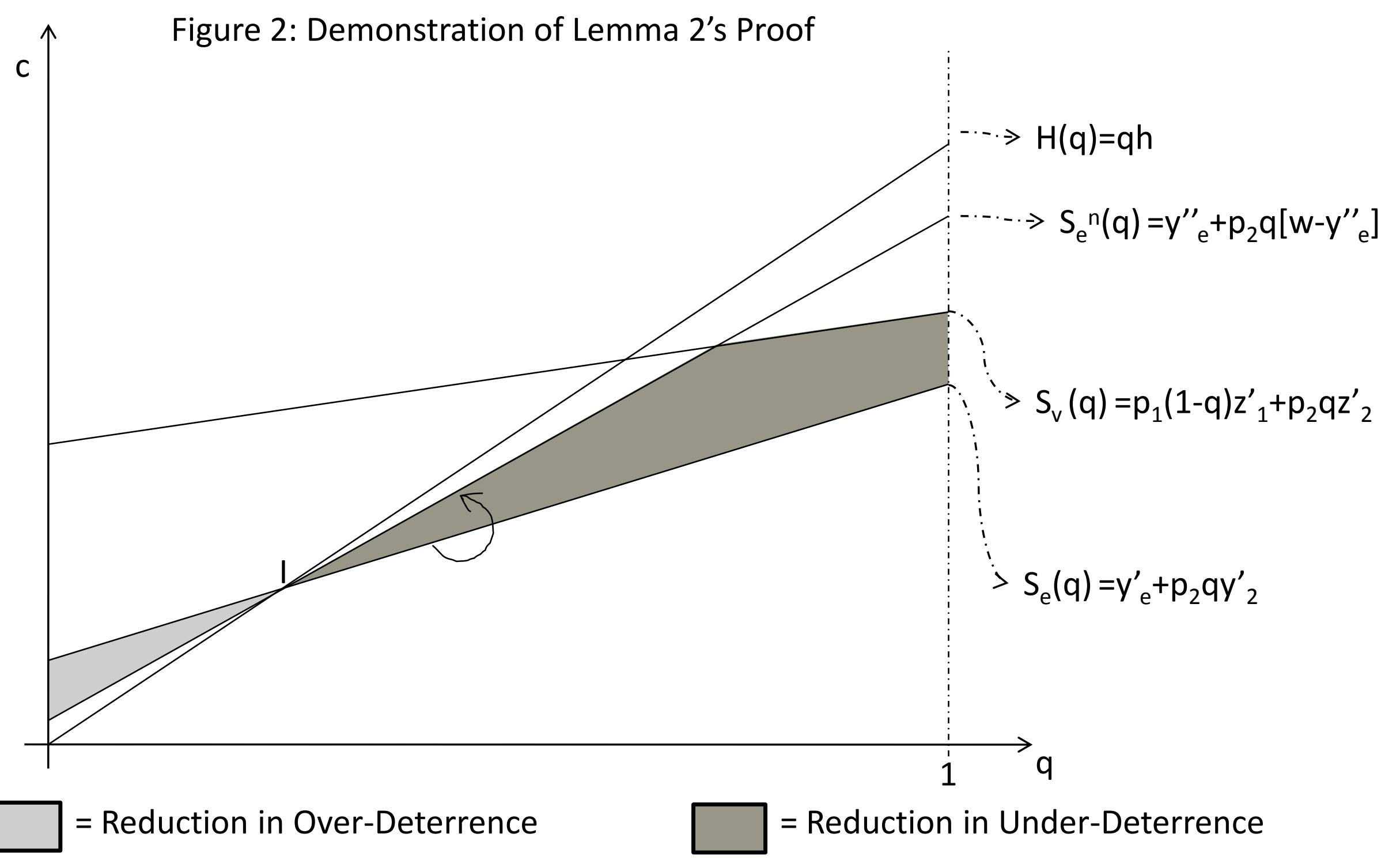


Figure 3: Demonstration of Lemma 3 part (i)

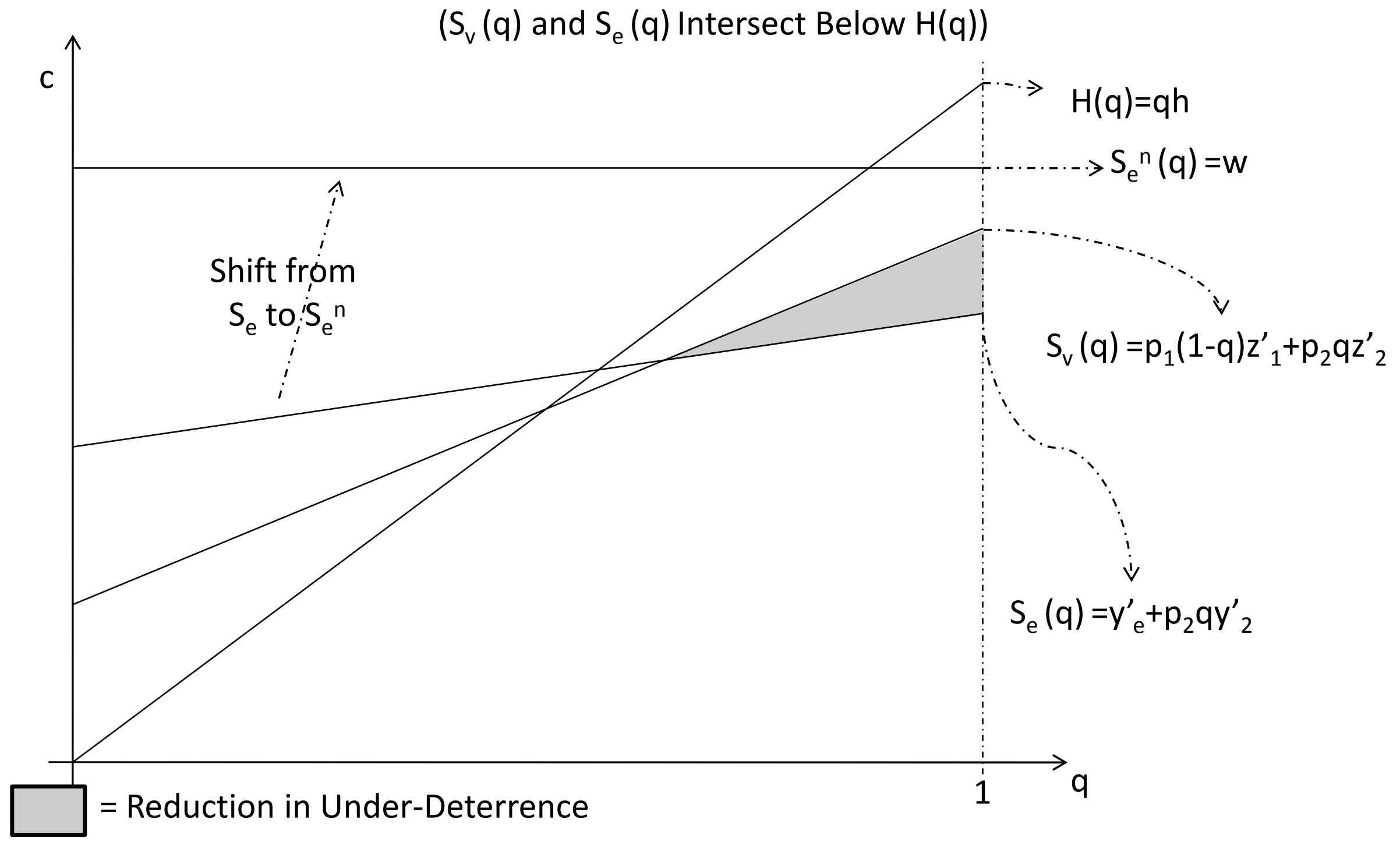


Figure 4: Demonstration of Lemma 3 part (ii) $\left(S_{v}(q)\right.$ and $S_{e}(q)$ Intersect Above $H(q)$ )

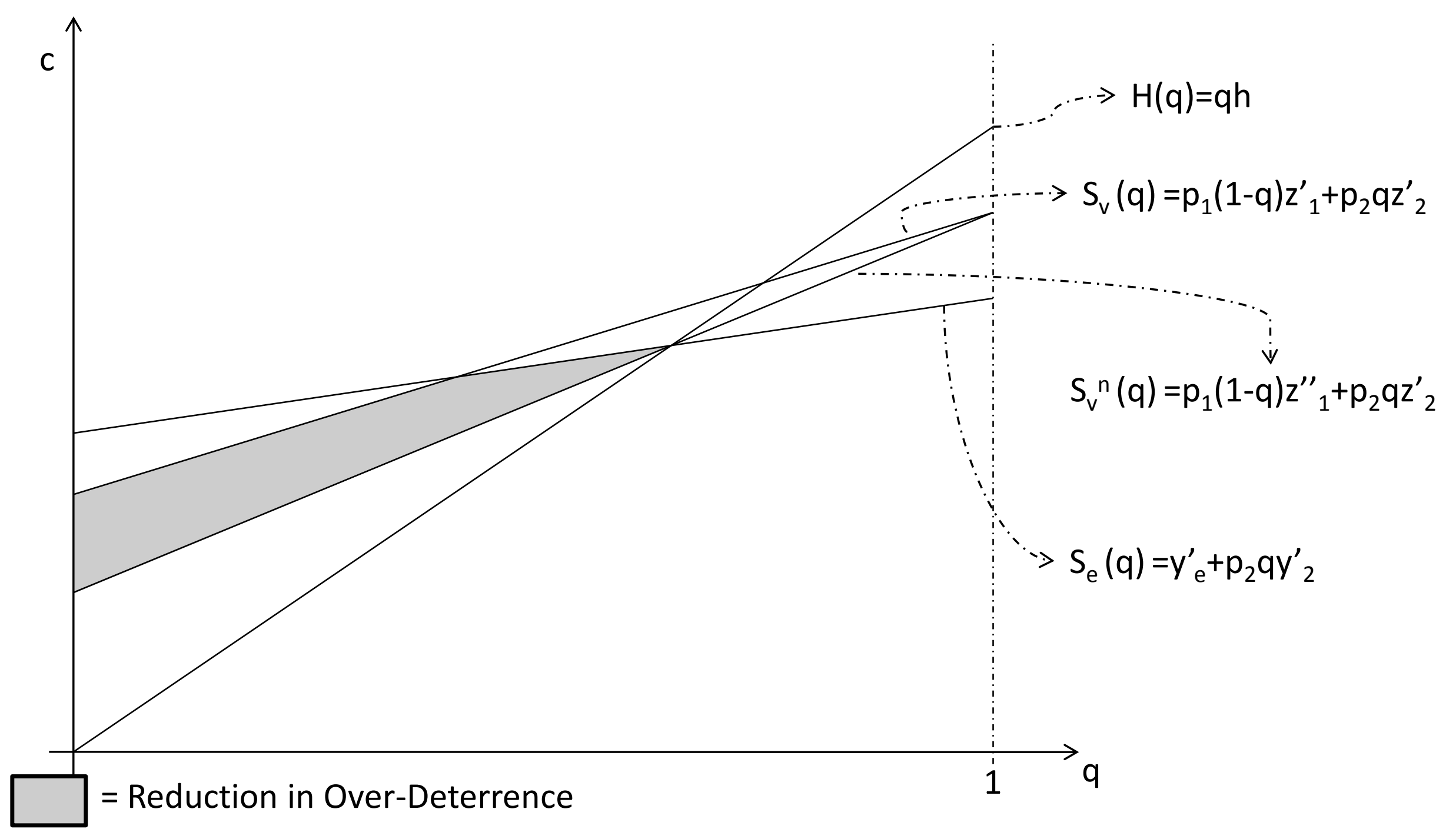




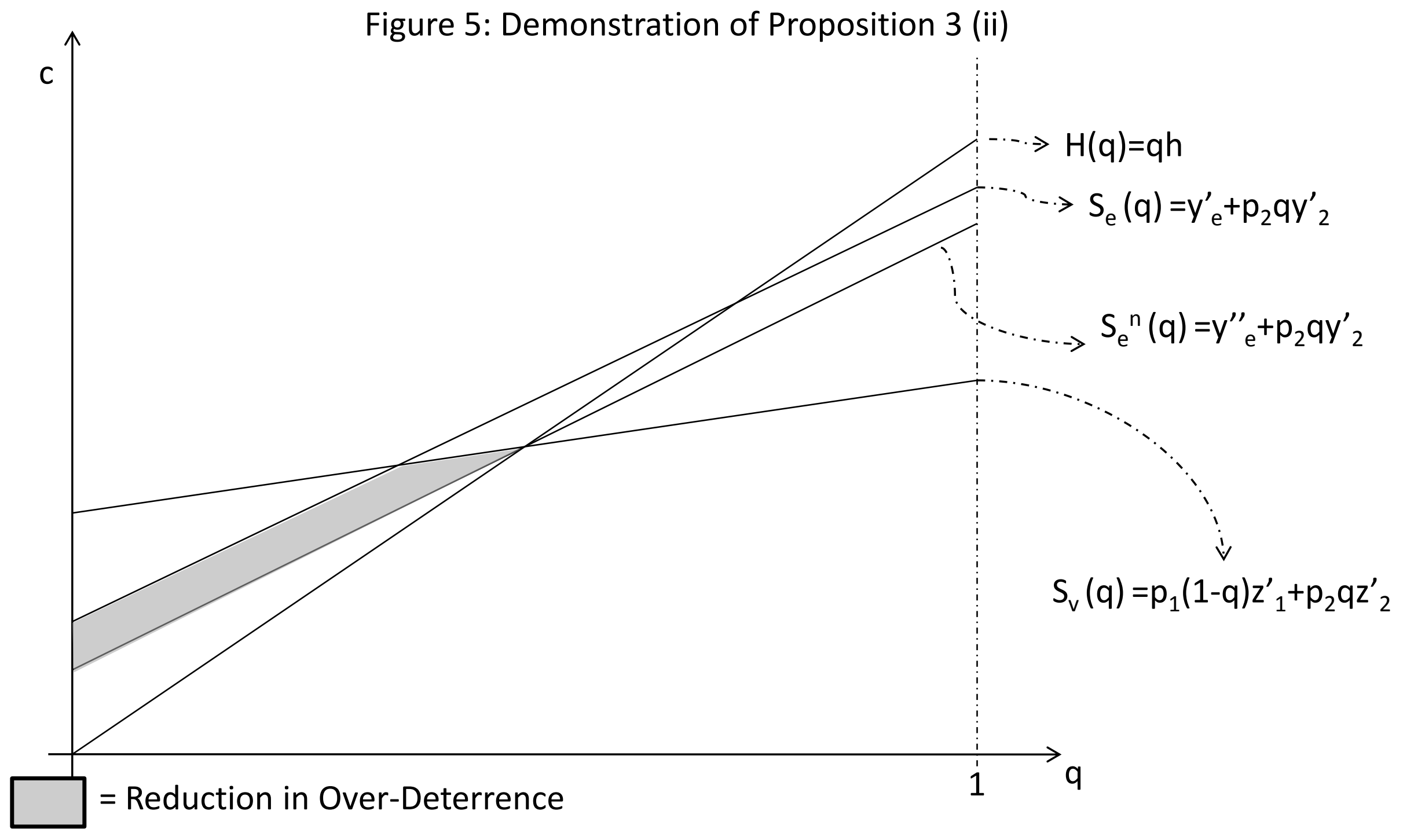




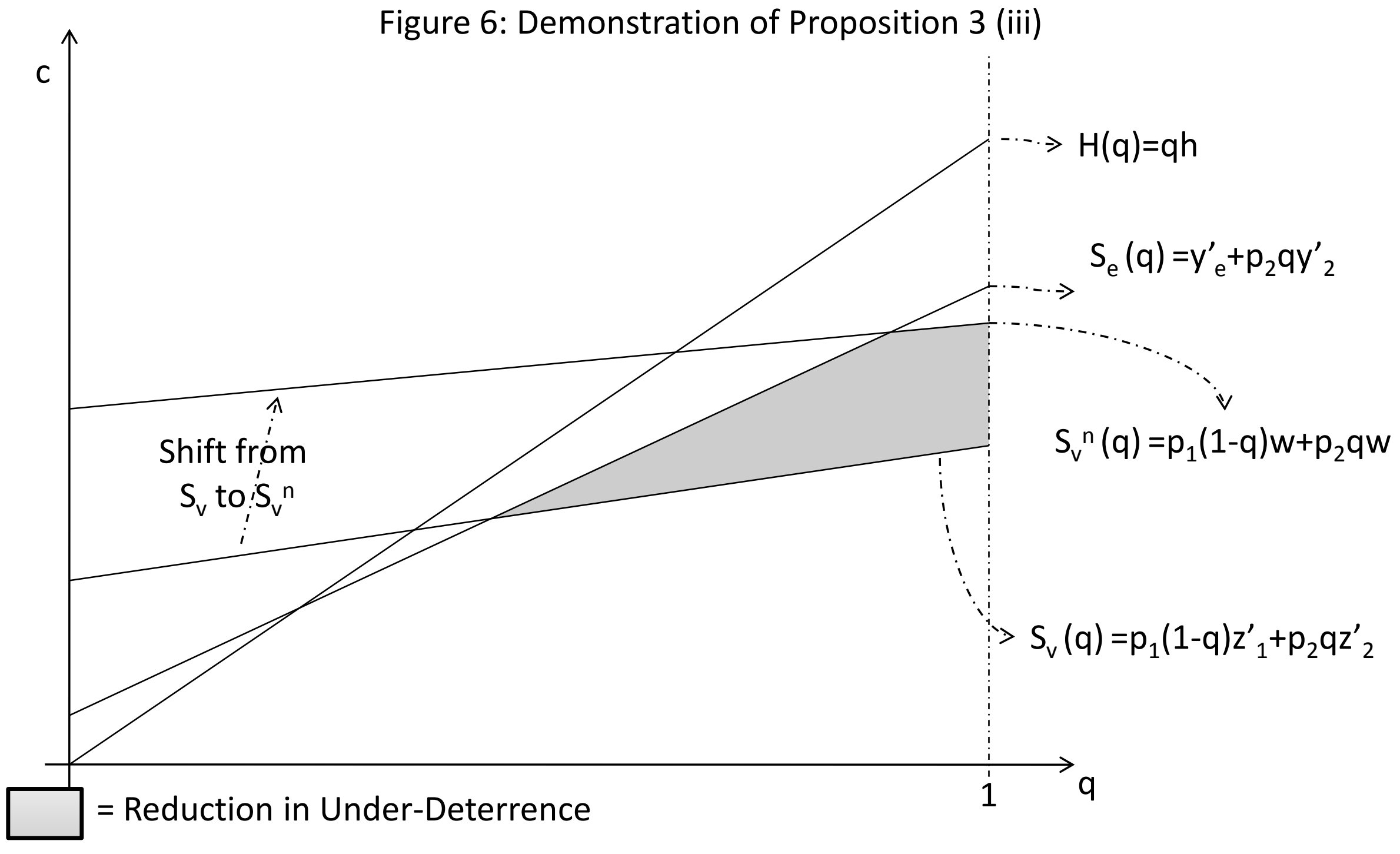




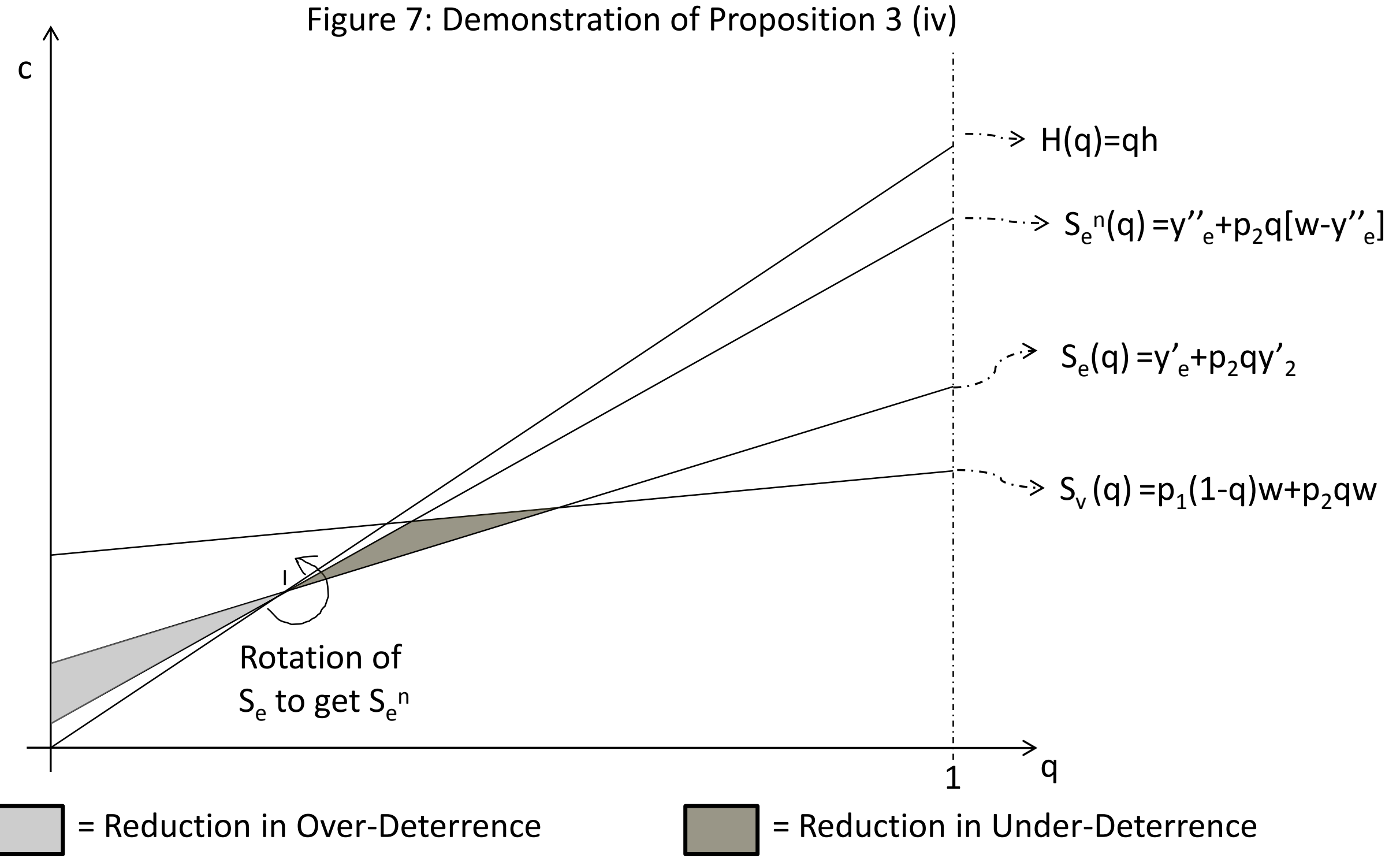

